Although exposure to asbestos is the most common cause of death from occupational lung disease, a recent survey clearly demonstrated poor awareness of the dangers of asbestos exposure amongst those trades-people most likely to be exposed to it. Since Do-It-Yourself (DIY) commonly results in asbestos exposure, we wondered whether homeowners are aware of the hazards of asbestos exposure in residential properties.

Methods A UK-wide, on-line questionnaire survey of homeowners was conducted among the 60000 users of 'Opinion Matters' to elicit their knowledge and views on asbestos between 18.05.2010 and 01.06.2010.

Results 2002 homeowners completing the questionnaire. 55\% live in homes built during the era when asbestos was commonly used as a building material. Respondents were predominantly from older age groups; knowledge about asbestos increased with the homeowner's age. When buying houses, $40 \%$ did not check whether the fabric of the home contained asbestos. $52 \%$ respondents had performed DIY in their homes and $23 \%$ were planning to do so within the year. While $60 \%$ respondents thought that asbestos had been used in residential building and refurbishments, 3\% believed that it had never been used and $12 \%$ believed that it was present only in factories and warehouse. 41\% thought that all asbestos has now been removed from residential buildings. Most respondents (88\%) sought professional advice regarding asbestos disposal but $3 \%$ just took it to the Council tip, $2 \%$ put it into their normal dustbins and $3 \%$ didn't know what to do with it. Some precautions were taken when undertaking DIY; 71\% respondents covered the furniture, $50 \%$ wore a dust mask and $43 \%$ wore protective overalls and goggles. However, only $29 \%$ checked for the presence of asbestos-containing materials (Abstract P12 Table 1).

Abstract P12 Table 1 Asbestos knowledge of home owner respondents-by age

\begin{tabular}{|c|c|c|c|c|c|c|}
\hline & Total & $\begin{array}{l}16-24 \\
\text { years }\end{array}$ & $\begin{array}{l}25-34 \\
\text { years }\end{array}$ & $\begin{array}{l}35-44 \\
\text { years }\end{array}$ & $\begin{array}{l}45-54 \\
\text { years }\end{array}$ & $\begin{array}{l}>55 \\
\text { years }\end{array}$ \\
\hline No. of respondents & 2002 & 9 & 252 & 451 & 540 & 750 \\
\hline $\begin{array}{l}\text { Know asbestos used as } \\
\text { building material (\%) }\end{array}$ & 39 & 11 & 28 & 34 & 39 & 46 \\
\hline $\begin{array}{l}\text { Not confident to identify } \\
\text { asbestos (\%) }\end{array}$ & 65 & 78 & 75 & 70 & 69 & 54 \\
\hline $\begin{array}{l}\text { Would ask for professional } \\
\text { to dispose of asbestos (\%) }\end{array}$ & 88 & 100 & 85 & 86 & 90 & 89 \\
\hline $\begin{array}{l}\text { Has never had information on } \\
\text { how to identify/mange asbestos }\end{array}$ & 58 & 67 & 53 & 61 & 58 & 51 \\
\hline $\begin{array}{l}\text { Have not heard of } \\
\text { mesothelioma (\%) }\end{array}$ & 61 & 56 & 74 & 65 & 63 & 53 \\
\hline
\end{tabular}

Conclusions Despite recent Health and Safety Executive awareness campaigns among trades-people, homeowners, including those who practice DIY, have dangerous misconceptions about the presence of asbestos in residential properties and have a poor grasp of essential safety precautions necessary for dealing with it. More effective public awareness campaigns are urgently required.

\section{P13 CLINICAL, RADIOGRAPHIC AND PULMONARY FUNCTION FINDINGS IN SILICOSIS}

doi:10.1136/thx.2010.150961.13

${ }^{1} \mathrm{CD}$ Lucas, ${ }^{2} \mathrm{~N}$ Hirani, ${ }^{2} \mathrm{AJ}$ Simpson, ${ }^{3} \mathrm{PT}$ Reid. ${ }^{1}$ University of Edinburgh / Department of Respiratory Medicine, Western General Hospital, Edinburgh, UK; ${ }^{2}$ University of Edinburgh / Department of Respiratory Medicine, Royal Infirmary of Edinburgh, Edinburgh, UK; ${ }^{3}$ Department of Respiratory Medicine, Western General Hospital, Edinburgh, UK

Introduction Silicosis is a pneumoconiosis caused by the inhalation of respirable silica. The condition is irreversible, and may be complicated by other pulmonary and non-pulmonary diseases. We describe clinical, radiographic and pulmonary function testing characteristics in a case series of silicosis.

Methods Cases were identified from clinics in two Edinburgh teaching hospitals. The diagnosis was based on characteristic radiographic features and a history of exposure to respirable silica; in two subjects silicosis was confirmed by surgical biopsy. Average length of follow up was 64 months.

Results 18 cases were identified, all were male. Median age = 52 years (range 28-66). 12 subjects worked as stonemasons, 5 as miners and 1 in a brick works. Common symptoms at presentation were dyspnoea (61\%), cough (44\%) and sputum (33\%) but one-third were entirely asymptomatic and identified by radiological screening. Asymptomatic subjects tended to be younger; median 41 (range $28-66$ ) vs 53 (range 28-66). 15 subjects (83\%) had an abnormal CXR; the remainder had abnormalities on HRCT only. PMF was present in 9 cases $(50 \%)$, one of whom was asymptomatic, and significant emphysema was present in 2 cases (11\%). $60 \%$ of subjects with simple silicosis had normal spirometry and normal transfer factor (TCO). Seven subjects had obstructive spirometry; four were ex- or current smokers (average 16.5 pack years) and three never smokers. Only three subjects had a restrictive defect on spirometry, two of whom had radiographic evidence of PMF. 81\% with a reduction in gas transfer had either a smoking habit or PMF Lymphopenia was present in six subjects. Ten subjects had immunology performed; four were positive for anti-nuclear antibodies; one subject had a pre-existing diagnosis of systemic sclerosis and one subsequently developed SLE. All subjects had normal renal function. Two subjects developed mycobacterium tuberculosis and two (both smokers) developed bronchogenic carcinoma.

Conclusions Despite the risks of silicosis being well described and legislation aimed at controlling silica exposure local experience suggests a resurgence of silicosis, particularly amongst younger workers who may be asymptomatic and may not have significant lung function changes.

\section{Clinical and experimental studies in asthma P14 DOES VITAMIN D AXIS HAVE AN EFFECT ON THE SEVERITY OF ASTHMA?}

doi:10.1136/thx.2010.150961.14

R Sathyamurthy, S Manney, A Wood, G Perkins, C Webster, MT Krishna, AH Mansur. Heart of England NHS Trust, Birmingham, UK

Background Vitamin D (VD) has been suggested to play a role in the development of asthma and frequency of asthma exacerbation ${ }^{1}$. Vitamin D Binding Protein (VDBP) is thought to influence the development of COPD through its immunomodulatory effect ${ }^{2}$. This study explores the role of vitamin $\mathrm{D}$ axis in relation to asthma severity.

Method An observational case control study with a healthy group $(\mathrm{H})$ and subgroups of severity of asthma - steroid 'naïve' mild asthma (MA), severe asthma (SA), severe asthma dependent on oral corticosteroids (SACS) and 'type 1 brittle' asthma (BA1) was conducted. VD, VDBP, spirometry, Fractional exhaled nitric oxide (FeNO) and exacerbations requiring oral corticosteroids/year (E) were recorded in all the patients. The data were analysed by Kruskal Wallis and Spearmans rank correlation test. The study was conducted between July 2009 and April 2010.

Results Sixty subjects [16M; mean age: 39years (19-57)] were recruited into this study. The parameters measured are shown in Abstract P14 Table 1. We observed no significant difference in serum VD between the healthy group and any of the asthma subgroups $(p=0.52)$, or indeed between all asthmatics grouped together and 